\title{
Prevalence and predictors of receipt of weight loss advice among a nationally representative sample of overweight and obese Kenyans
}

\author{
Cort Wernz ${ }^{1}$, Rahma S Mkuu ${ }^{2}$, Nicholas Leal ${ }^{1}$, Raven Stegall ${ }^{1}$, Caroline Wekullo ${ }^{3}$, \\ Dawit Woldu ${ }^{4}$ Idethia Shevon Harvey ${ }^{1,2}$
}

1. Department of Health and Kinesiology Texas A\&M University, TX.

2. Transdisciplinary Center for Health Equity Research Texas A\&M University, TX.

3. Department of Educational Administration and Human Resource Development, Texas A\&M University, TX.

4. Medical Anthropology, College of Human Sciences and Humanities.

5. University of Houston - Clear Lake.

\section{Author details:}

Rahma S Mkuu: Phone: 352.222.6615, Email: rahmamkuu@gmail.com; Nicholas Leal: Phone: 956.639.2480, Email: nicklea154@tamu.edu; Raven Stegall: Phone: 409.656.0119, Email: rstegall98@tamu.edu; Caroline Wekullo: Email cweullo@tamu. edu; Dawit Woldu: Email: woldu@uhcl.edu

\begin{abstract}
Background: As Kenya continues to experience rapid development and urbanization, growing evidence shows an increasing prevalence of non-communicable diseases (NCDs) and overweight and obese citizens.

Objectives: This study sought to explore the extent to which Kenyan overweight and obese participants reported receiving advice from physicians or health care providers to lose weight and to identify demographic characteristics associated with receipt of weight loss advice.

Methods: Descriptive statistics analyzed sociodemographic characteristics and weight loss advice from the 2015 Kenya WHO STEPwise survey $(\mathrm{n}=1335)$. A bivariate logistic regression model estimated the association between socio-demographic characteristics and weight loss advice reported from a physician or health care provider.

Results: The prevalence of weight loss advice from health professionals among overweight and obese participants was $19 \%$. Model results indicated that obese individuals [odds ratio $(\mathrm{OR})=2.11,95 \%$ confidence interval $(\mathrm{CI})(1.36,3.26)$ ], individuals with higher than a secondary education [OR $=2.26,95 \% \mathrm{CI}(1.39,3.68)]$, urban dwellers [OR $=2.38,95 \% \mathrm{CI}(1.29,4.39)]$, and women $[\mathrm{OR}=3.13,95 \% \mathrm{CI}(1.60,6.12)]$ were significantly more likely to receive weight loss advice from their physician or health care provider.

Conclusion: This study found low levels of report of physician or health care provider advice for weight loss among overweight individuals. Advice was primarily reported by obese patients. Weight loss advice differed significantly based on educational attainment, geographical location, and gender thus calling for targeted interventions to increase equitable NCD prevention services from physicians.
\end{abstract}

Keywords: Receipt of weight loss advice; overweight; obese Kenyans.

DOI: https://doi.org/10.4314/ahs.v20i2.45

Cite as: Wernz C, Mkun RS, Leal N, Stegall R, Wekullo C, Woldu D, et al. Prevalence and predictors of receipt of weight loss advice among a nationally representative sample of overweight and obese Kenyans. Afri Health Sci. 2020; 20(2): 903-911. https:// doi.org/10.4314/abs. v20i2.45

\section{Corresponding author:}

Cort Wernz,

Department of Health and Kinesiology Texas A

\&M University, TX. Phone: 208.860.8707,

Address: 4151 Wellborn Rd., Apt 2104, Bryan,

TX 77801.

Email: cort@tamu.edu; Idethia Shevon Harvey,

Department of Health and Kinesiology Center

Director, Transdisciplinary Center for Health

Equity Research Texas A\&M University, TX.

Phone: 979.862.2954. Email: isharvey@tamu.edu

\section{Introduction}

Rates of overweight and obese individuals have been consistently increasing globally. The pandemic obesity prevalence rates have proven to be much more substantial in low- and middle-income countries (LMICs) compared to high-income countries ${ }^{1}$. Women are significantly more likely to be overweight or obese compared to men in LMICs ${ }^{2}$. In Kenya, the prevalence rate of overweight and obesity mimics high-income countries. For example, approximately $30 \%$ of the population of Kenya is classified as being either "overweight" or 
“obese," with prevalence rates being significantly higher among women $(39 \%)$ compared to men $(18 \%)^{3}$.

Kenya has been going through a demographic transition with a declining number of people residing in traditional rural settings and increasing urban dwellers. As of the most recent World Bank Population estimates in 2016, one-third of Kenya's population resided in an urban setting, and urban population has continued to steadily grow each year at a rate of $4.3 \%{ }^{4}$. Urbanization has been attributed to much of the increase in overweight and obese Kenyans. Kenyan urban dwellers are twice as likely to be either overweight or obese compared to rural dwellers ${ }^{3}$. While rural Kenyans have traditionally relied on agriculture for food supplies, urban Kenyans are increasingly relying on modern supermarkets. This may be explained by rural to urban migration diluting some cultural and traditional dietary behaviors, which may be a contributing factor to the rise of obesity in Kenya. Furthermore, physical and labor work commonly associated with rural life creates a more energy intensive lifestyle compared to urban lifestyle. Corresponding with the movement of populations toward major cities, per capita income in Kenya has increased more than 50\% during the past decade ${ }^{5}$. Studies have shown that shopping at supermarkets has led to a dramatic increase in consumption of processed foods. These processed foods are correlated with higher risk of obesity in Kenya ${ }^{6}$.

Wealthy Kenyans are up to five times as likely to be overweight or obese when compared to poor Kenyans ${ }^{7}$. The difference in obesity outcomes by wealth has been attributed to high-income Kenyans being more likely to consume obesogenic diets characterized by a high proportion of processed, high sugar, and high-fat foods ${ }^{8}$. Despite the disproportionate impact on the wealthy, overweight and obese individuals in Kenya are also increasingly becoming an issue among the poor, especially individuals living in urban settings. Nearly $45 \%$ of female and $20 \%$ of male slum dwellers in Nairobi, Kenya, were either overweight or obese according to a recent study ${ }^{9}$. The changes in dietary habits, accompanied by urbanization, irrespective of income level, appear to be a driving factor behind the increase in body mass ${ }^{10}$.

Kenyan physicians and health care providers are in a unique position to ameliorate the escalation of their overweight and obese patients by educating overweight patients and guiding them toward a healthier lifestyle. Although research in Africa examining the relationship between physician advice and weight loss is extremely limited, American researchers have consistently shown that overweight and obese patients are more likely to take steps to lose weight as a result of receiving physician advice ${ }^{11,12}$. Banjeree and colleagues found that obese African American patients who were encouraged by their primary care physician to lose weight reported higher levels of motivation to initiate healthy lifestyle changes compared to patients who did not receive weight loss advice. In addition, the patients who received weight loss advice ultimately lost more weight compared to participants who did not receive physician advice ${ }^{11}$. Similarly, researchers who studied obese pre-diabetic adults found that these individuals were more likely to modify their diet and increase their physical activity after receiving recommendations from their physician ${ }^{12}$. Finally, Harris and colleagues found that obese African American patients had a more accurate perception of their bodyweight and would take steps to reduce their bodyweight if their physicians initiated a discussion regarding bodyweight ${ }^{13}$.

In Kenya, several studies provide evidence of a high prevalence of overweight and obese individuals ${ }^{8,9}$, however, a literature gap exists in understanding the current overweight and obesity management and prevention efforts in the country. Given the evidence that physician weight loss advice significantly influences weight loss among patients, this study aimed to examine the extent to which overweight or obese Kenyans receive physician or care provider recommendations for weight loss. Additionally, this study sought to identify demographic characteristics associated with receipt of weight loss advice from a physician or healthcare professional.

\section{Methods \\ Sample}

The study utilized data from the 2015 Kenya World Health Organization (WHO) STEPwise survey NCD risk factors. The survey is the first nationally representative survey in Kenya to collect anthropometric measurements (e.g., height, weight, and blood pressure), biochemical measurements (e.g., blood glucose), and dental assessments (e.g., oral care) equally among men and women. The survey is the first to collect comprehensive information on NCD risk factors, unintentional injuries, and behavioral risk factors in the country.

The cross-sectional survey used the fifth National Sample Surveys and Evaluation Programme (NASSEP V) master sampling frame of the Kenya National Bureau 
of Statistics, which involved a three-cluster sampling frame design. First, 100 rural and 100 urban-cluster areas were selected from the NASSEP V sampling frame. Second, 30 households were selected from each cluster. Third, individuals were selected randomly from households by gender and by 12-year increment age groups. Overall 6,000 households were sampled of which 4,754 individuals consented to participate in the survey A total of 4,500 individuals consented and participated, yielding a response rate of $95 \%$. More detailed information on the sampling frame is published in the 2015 Kenya STEPwise report ${ }^{4}$. For this study, only adults who were overweight or obese were included in the analysis ( $\mathrm{n}=$ $1,355)$.

\section{Outcome Variable}

The outcome variable focused on the physician recommendation for weight loss. Participants were asked, "During the past three years, has a doctor or other health worker advised you to maintain a healthy body weight or lose weight?" Participants who responded "yes" to receiving advice were identified to have "received advice". Receiving advice was dummy coded as "1" for received advise, and " 0 " who "did not receive advice."

\section{Covariates}

\section{Demographic Variables}

Biological sex was dummy coded " 0 " for "female" participants and "1" for "male" participants. Age was provided as a continuous variable and as a categorical variable consisting of 12 -year increment age groups (“18-29," “30-44," “45-59," and "60-69”). Categorical age groups were used for descriptive statistics, and the continuous measure was used in the logistic regression model. Participant residence was dummy coded " 0 " for "rural" and "1" for "urban neighborhoods." The "wealth index," which was a measure of the level of wealth status by examining household assets, was classified into five categories ("poorest," "poor," "middle," "rich," and "richest") and used in the descriptive analysis. "Wealth index" was dummy coded " 0 " for "poorest to poor" and " 1 " for "middle to richest" wealth and used in the bivariate logistic regression model. The "education" level was coded in the following categories: "no formal education," "some primary school," "completed primary school," and "secondary education or above." For the bivariate logistic regression model, "education" was dummy coded "0" for "below secondary education" and " 1 " for "secondary education or above." "Marital status" was divided into five cate- gories: "cohabitating," "married," "divorced," "separated," and "widowed."

\section{Anthropometric Measures}

The survey collected weight in kilograms (kg) and height in centimeters. The body mass index (BMI) was calculated by kilograms divided by meters squared $(\mathrm{kg} /$ $\mathrm{m} 2$ ). "Overweight" was defined as having a BMI between "25" and "29.99," and "obese" as having a BMI of "30 or above” (World Health Organization, 2018).

\section{Non-communicable Diseases (NCDs)}

Three blood pressure measurements were measured using an Omron Blood Pressure machine following WHO STEPwise guidelines ${ }^{4}$. The average of the last two systolic blood pressure (SBP) and diastolic blood pressure (DBP) readings was used to determine hypertension levels. Hypertension was defined as having an average SBP greater than or equal to $140 \mathrm{mmHg}$ and mean DBP above $90 \mathrm{mmHg}$, or self-reported use of antihypertensive medication. A fasting blood glucose measurement was measured according to the WHO STEPwise survey ${ }^{4}$. Having type 2 diabetes (T2D) was defined by a fasting blood glucose measure equal to or above $7 \mathrm{mmol} / \mathrm{L}(126 \mathrm{mg} / \mathrm{dl})$ or currently taking insulin.

\section{Analysis}

Survey data were analyzed using STATA 14. Data were weighted to account for complex sampling methods during analysis. Descriptive statistics were calculated by determining proportions for categorical variables and means for continuous variables. Likelihood-ratio chi-square tests were performed to assess goodness of fit to identify whether ordinal variables found to be associated with obesity in previous studies were significant as a whole or not ${ }^{9}$. A bivariate logistic regression model examined the physician's recommendation to maintain a healthy bodyweight or to lose weight among overweight and obese participants while controlling for demographic characteristics (e.g., age, sex, education, wealth, residence and marital status, and NCDs). The demographic variables and NCDs in the model were informed by studies demonstrating significant relationships between the variables ${ }^{8,-10,15,25,28}$.

\section{Results}

The average age of participants was 37.20 years, with a majority of $72.98 \%$ under the age of 44 years. The sample consisted of $68.17 \%$ women and $32.82 \%$ men. The study consisted of $49.68 \%$ rural residents and 
$50.31 \%$ urban resdents. More than half of the sample identified as being in the "rich" and "richest" categories $(58.13 \%)$. The majority had at least completed primary education $(75.76 \%)$ and were married $(72.63 \%)$. One-third of participants $(32.35 \%)$ were obese. Only $18.68 \%$ of participants reported receiving weight loss advice from a physician or health provider. Descriptive results are provided in Table 1. Bivariate likelihood-ratio chi-square results demonstrated that there were significant differences for receiving weight loss advice by gender, location, wealth, and high blood pressure. Bivariate analysis results are provided in Table 2.

Table 1: Socioeconomic, demographic, and anthropometric characteristic of the study participants by overweight/obesity status, 2015 Kenya WHO STEPwise survey $(n-1335)$

\begin{tabular}{|c|c|c|c|c|}
\hline & Proportion & $\begin{array}{l}\text { Std. } \\
\text { Err }\end{array}$ & $\begin{array}{l}\text { (98\%) Confidence } \\
\text { Min. }\end{array}$ & $\begin{array}{c}(95 \%) \text { Confidence } \\
\text { Max }\end{array}$ \\
\hline \multicolumn{5}{|l|}{ Age Groups } \\
\hline $18-29$ & $35.21 \%$ & 0.03 & 0.29 & 0.41 \\
\hline $30-44$ & $37.77 \%$ & 0.02 & 0.33 & 0.42 \\
\hline $45-59$ & $20.82 \%$ & 0.01 & 0.17 & 0.24 \\
\hline $60-69$ & $6.18 \%$ & 0.01 & 0.04 & 0.08 \\
\hline \multicolumn{5}{|l|}{ Gender } \\
\hline Men & $31.82 \%$ & 0.03 & 0.26 & 0.38 \\
\hline Women & $68.17 \%$ & 0.03 & 0.62 & 0.73 \\
\hline \multicolumn{5}{|l|}{ Location } \\
\hline Rural & $49.68 \%$ & 0.05 & 0.40 & 0.60 \\
\hline Urban & $50.31 \%$ & 0.05 & 0.40 & 0.60 \\
\hline \multicolumn{5}{|l|}{ Wealth } \\
\hline Poorest & $8.03 \%$ & 0.01 & 0.05 & 0.11 \\
\hline Poor & $14.77 \%$ & 0.02 & 0.11 & 0.19 \\
\hline Mid & $19.05 \%$ & 0.02 & 0.15 & 0.24 \\
\hline Rich & $21.64 \%$ & 0.02 & 0.17 & 0.27 \\
\hline Richest & $36.49 \%$ & 0.05 & 0.03 & 0.48 \\
\hline \multicolumn{5}{|l|}{ Education } \\
\hline $\begin{array}{l}\text { No formal schooling } \\
\text { Primary school }\end{array}$ & $6.71 \%$ & 0.01 & 0.05 & 0.09 \\
\hline incomplete & $18.52 \%$ & 0.02 & 0.14 & 0.22 \\
\hline $\begin{array}{l}\text { Primary school complete } \\
\text { Secondary \& above }\end{array}$ & $34.42 \%$ & 0.03 & 0.29 & 0.40 \\
\hline school & $41.34 \%$ & 0.04 & 0.34 & 0.50 \\
\hline \multicolumn{5}{|l|}{ Marital Status } \\
\hline Cohabitating & $0.64 \%$ & 0.01 & 0.00 & 0.02 \\
\hline Married & $72.63 \%$ & 0.02 & 0.68 & 0.77 \\
\hline Divorced & $0.90 \%$ & 0.01 & 0.00 & 0.02 \\
\hline Never Married & $15.81 \%$ & 0.02 & 0.03 & 0.05 \\
\hline Separated & $3.89 \%$ & 0.01 & 0.03 & 0.05 \\
\hline Widowed & $6.13 \%$ & 0.01 & 0.05 & 0.08 \\
\hline \multicolumn{5}{|l|}{ Obese } \\
\hline Not Obese & $67.64 \%$ & 0.02 & 0.64 & 0.71 \\
\hline Obese & $32.35 \%$ & 0.02 & 0.29 & 0.36 \\
\hline \multicolumn{5}{|l|}{ Weight Loss Advice } \\
\hline No & $81.31 \%$ & 0.02 & 0.76 & 0.86 \\
\hline Yes & $18.68 \%$ & 0.02 & 0.14 & 0.24 \\
\hline
\end{tabular}


Table 2: Bivariate results of Socioeconomic, demographic, and anthropometric characteristic of participants by receipt of advice to lose weight , 2015 Kenya WHO STEPwise survey ( $\mathrm{n}$ 1335)

\begin{tabular}{|c|c|c|c|c|}
\hline & $\begin{array}{c}\text { Proportion } \\
\text { Received } \\
\text { Advice }\end{array}$ & $\begin{array}{l}\text { Proportion } \\
\text { Did Not } \\
\text { Receive } \\
\text { Advice }\end{array}$ & chi-square value & $\mathrm{p}$ value \\
\hline \multicolumn{5}{|l|}{ Age Groups } \\
\hline $18-29$ & $3.14 \%$ & $28.66 \%$ & \multirow{4}{*}{2.94} & \multirow{4}{*}{0.82} \\
\hline $30-44$ & $3.81 \%$ & $34.99 \%$ & & \\
\hline $45-59$ & $2.10 \%$ & $17.68 \%$ & & \\
\hline $60-69$ & $1.04 \%$ & $8.46 \%$ & & \\
\hline \multicolumn{5}{|l|}{ Sex } \\
\hline Men & $2.94 \%$ & $36.88 \%$ & \multirow{2}{*}{24.51} & \multirow{2}{*}{$<0.01$} \\
\hline Women & $7.16 \%$ & $52.90 \%$ & & \\
\hline \multicolumn{5}{|l|}{ Location } \\
\hline Rural & $4.25 \%$ & $47.26 \%$ & \multirow{2}{*}{17.72} & \multirow{2}{*}{$<0.01$} \\
\hline Urban & $5.85 \%$ & $42.52 \%$ & & \\
\hline \multicolumn{5}{|l|}{ Wealth } \\
\hline Poorest & $0.76 \%$ & $19.37 \%$ & \multirow{5}{*}{90.21} & \multirow{5}{*}{$<0.01$} \\
\hline Poor & $1.57 \%$ & $18.42 \%$ & & \\
\hline Mid & $1.87 \%$ & $18.21 \%$ & & \\
\hline Rich & $2.94 \%$ & $16.92 \%$ & & \\
\hline Richest & $2.96 \%$ & $16.87 \%$ & & \\
\hline \multicolumn{5}{|l|}{ Education } \\
\hline No formal education & $0.53 \%$ & $16.22 \%$ & \multirow{4}{*}{76.95} & \multirow{4}{*}{$<0.01$} \\
\hline Primary school incomplete & $2.40 \%$ & $22.07 \%$ & & \\
\hline Primary school complete & $3.22 \%$ & $28.44 \%$ & & \\
\hline Secondary \& above complete & $4.09 \%$ & $22.91 \%$ & & \\
\hline \multicolumn{5}{|l|}{ Marital Status } \\
\hline Cohabitating & $0.02 \%$ & $0.58 \%$ & \multirow{6}{*}{7.61} & \multirow{6}{*}{0.82} \\
\hline Married & $6.84 \%$ & $60.33 \%$ & & \\
\hline Divorced & $0.24 \%$ & $1.47 \%$ & & \\
\hline Never Married & $1.67 \%$ & $15.84 \%$ & & \\
\hline Separated & $0.51 \%$ & $4.62 \%$ & & \\
\hline Widowed & $0.96 \%$ & $6.78 \%$ & & \\
\hline \multicolumn{5}{|l|}{ Weight Status } \\
\hline Not Obese & $0.00 \%$ & $0.14 \%$ & \multirow{2}{*}{0.68} & \multirow{2}{*}{0.71} \\
\hline Obese & $10.10 \%$ & $89.65 \%$ & & \\
\hline \multicolumn{5}{|l|}{ Hypertension } \\
\hline Yes & $1.76 \%$ & $13.08 \%$ & \multirow{2}{*}{19.15} & \multirow{2}{*}{$<0.01$} \\
\hline No & $8.34 \%$ & $76.70 \%$ & & \\
\hline \multicolumn{5}{|l|}{ Type-2 Diabetes } \\
\hline Yes & $10.10 \%$ & $89.37 \%$ & \multirow{2}{*}{2.06} & \multirow{2}{*}{0.36} \\
\hline No & $0.00 \%$ & $0.42 \%$ & & \\
\hline
\end{tabular}

The bivariate logistic model regression found that women were significantly more likely to receive advice from a doctor to lose weight compared to men (OR:3.13, 95\% CI: 1.60-6.12), controlling for demographic characteristics and NCDs. Individuals living in urban areas were significantly more likely to receive advice compared to rural dwellers (OR:2.38, 95\% CI: 1.29-4.39), controlling for demographic characteristics and NCDs. Individuals who completed secondary education or more were significantly more likely to receive advice compared to those with less than complete secondary education (OR:2.26, 95\% CI:1.39-3.68), controlling for demographic characteristics and NCDs. Obese individuals, compared to overweight individuals, were significantly more likely to receive weight loss advice from a physician or health provider (OR: 2.11, 95\% CI: 1.36-3.26), controlling for demographic characteristics and NCDs. Bivariate results are provided in Table 3. 
Table 3: Estimates of odds ratios and confidence intervals of different correlates of overweight and obesity, 2015 Kenya WHO STEPwise survey ( $\mathrm{n}-1335)$

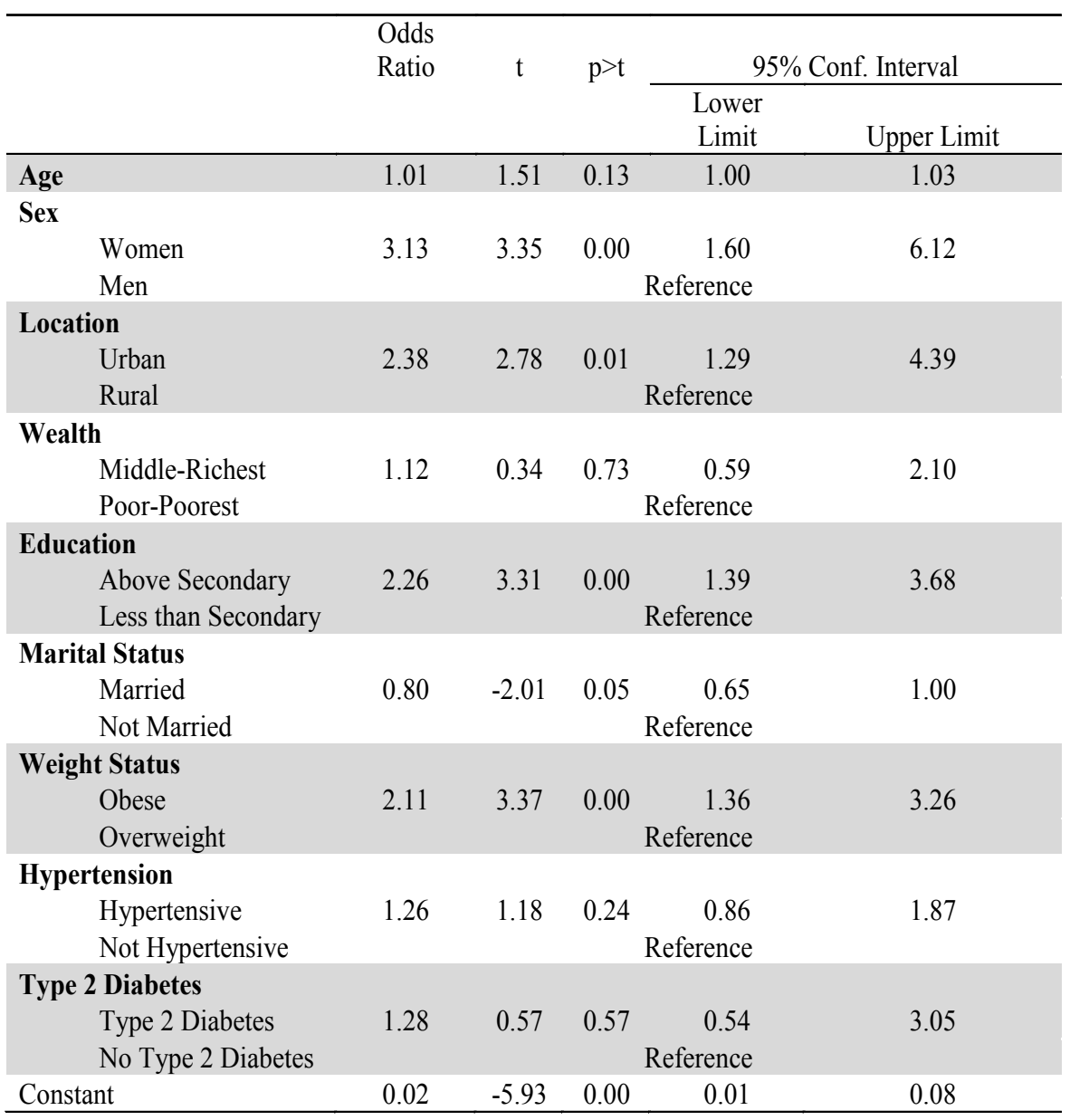

\section{Discussion}

The purpose of this study was to examine the extent to which overweight or obese individuals in Kenya reported that they received advice from their physicians or healthcare provider to lose weight. Individuals who were obese, female, residing in urban areas, and participants who completed secondary education, were significantly more likely to receive weight loss advice from their physician or healthcare provider. Our study found that only $18.68 \%$ of the sample reported receiving weight loss advice.

The low prevalence of reporting physician or healthcare provider weight loss recommendations corresponds with findings from previous studies conducted in the West. One study conducted in Great Britain examined a large sample of overweight and obese individuals at middle income levels and found that only $17 \%$ of overweight and $42 \%$ of obese participants had ever received advice to lose weight from their physician or care provider ${ }^{14}$. Another study surveyed low income racial/ethnic minorities in the United States reported that only $35 \%$ of overweight or obese respondents reported that they had received advice to lose weight from their primary care physician ${ }^{15}$

Physicians and healthcare providers in Kenya might be hesitant to provide weight loss advice to patients because of cultural and religious reasons ${ }^{16}$. Despite current changes in body weight perception in urban Africa, overweight and obesity has historically been seen in positive light in many cultures in the region ${ }^{17}$. Body weight and thickness is culturally associated with power, wealth, health, and prosperity in many African societies $^{18}$.

Overweight and obese are widely accepted as leading health risk factors to $\mathrm{NCDs}^{19}$. Studies show that weight loss can result in improving health outcomes such as type 2 diabetes ${ }^{20}$. Additionally, overweight and obese individuals are significantly more likely to report losing at least $5 \%$ weight as a result of physicians' advice to lose weight ${ }^{21}$. The low proportion of participants reporting weight loss advice from their physicians may be a result of lack of preventive medicine training or lack of emphasis on NCD prevention ${ }^{22}$. In Kenya, as with other LMICs facing a double burden of both NCDs and infectious diseases, physicians and healthcare staff 
may be overburdened with the volume of patients and may have to provide primary care with limited resourc$\mathrm{es}^{23}$. Future studies should seek to understand physician and healthcare provider practices, such as prevention and counseling of health behaviors, to understand the facilitators and barriers to providing physicians' weight loss advice.

In this study, women were three times more likely to report receiving advice to lose weight from a physician or healthcare provider compared to men. Globally, women have the highest prevalence rate of being overweight and obese ${ }^{24}$. The high prevalence of overweight and obesity among women has been associated with NCDs, as well as adverse maternal outcomes ${ }^{25}$. The leading adverse maternal health outcomes, such as gestational diabetes, preeclampsia, congenital disabilities, and miscarriages, are associated with overweight or obesity ${ }^{26}$. Since reproductive women are more likely than men to obtain preventive care, they may be more likely to receive weight loss recommendations compared to men.

Geographical locations were also associated with weight loss advice. Individuals living in urban areas were twice as likely to report receiving advice to lose weight compared to participants residing in rural areas. In Kenya, urban dwellers have been reported to be significantly more likely to be overweight compared to rural dwell$\mathrm{ers}^{3,8}$. One explanation of our findings is that health care providers who are located in urban areas may be more likely to be aware of the negative health effects of being overweight or obese due to higher prevalence rats of obesity in urban areas ${ }^{27}$. Recent findings reported that metropolitan cities in Kenya, such as Nairobi and Mombasa, had the highest number of cardiologists ${ }^{27}$. Physicians practicing in urban areas may also be more likely to receive continuing medical education (CME) on the latest health challenges or trends. Research is needed to examine physicians' CME to determine if education impacts their recommendations for weight loss.

This study found that individuals, who completed secondary education (e.g., grades 9 through 12), were twice as likely to receive weight loss advice compared to those who did not complete secondary education. Previous studies conducted in the United States have also discovered that overweight and obese individuals with a higher educational status are more likely to be counseled by their physician to lose weight compared individuals with a lower educational attainment ${ }^{28}$. Receipt of weight loss advice due to high education attainment may be explained by empowerment, ability to commu- nicate or ask physicians questions about health status, and better access to medical care.

To the authors' surprise, the wealth category was not a significant factor in determining the likelihood of overweight and obese Kenyans receiving weight loss advice from their physicians. Although previous studies conducted in the United States have found that wealthier individuals are more likely to be counseled to lose weight by their physicians29, our findings suggest that income level does not play a major factor in Kenya.

Obese individuals, compared to overweight individuals, were significantly more likely to receive weight loss advice. Obese individuals may be more likely to receive weight loss advice due to perceived severity of their condition. Previous studies show that physicians are more likely to give weight loss advice if participants are obese or have at least one NCD14,28. Our study did not find significant findings on receiving weight loss advice associated with a diagnosis of NCDs (i.e., T2D or Hypertension).

Although our study centered around patient demographics, previous research has found the possibility of certain characteristics associated with physicians themselves that can impact the likelihood of them providing weight loss advice to their overweight or obese patients. One study conducted in the United States showed that patients who were seen by female doctors were significantly more likely to be referred to obesity treatment ${ }^{29}$. Another study found that younger physicians, as well as physicians who received obesity prevention educational training, were more likely to give weight loss advice compared to older physicians and those physicians who did not have CME about obesity prevention ${ }^{30}$. More studies are needed to ascertain the scope of physician NCD prevention in Kenya including examining evidence-based strategies, such as providing weight loss advice.

\section{Strengths and Limitations}

Our study has some limitations. First, the use of crosssectional data limits the ability to determine trends over time. Second, the use of secondary data limited control and access to variables available. In this study, physician or healthcare provider advice to lose weight was measured using one variable that asked participants if they have ever been advised to lose weight by a physician or health care worker. Having access to information on the type of hospital or clinic attended, or more information on health care worker characteristics (whether 
it was specifically a doctor or nurse) would have provided more information to ascertain factors associated with care and management. Furthermore, this study had very limited information regarding cultural factors that could influence physicians or healthcare providers to provide advice to patients.

Despite limitations, this study has several strengths. The use of the WHO STEPWise survey is a strength as it is a nationally representatives survey, and the survey is recognized as a reliable instrument globally. Another strength is that being considered overweight or obese was based on objective measures and not self-report. To our knowledge, this is the first study examining physicians' and health care professional advice to overweight or obese patients to lose weight in Kenya.

\section{Conclusion}

This study found that only 19\% of overweight or obese individuals in Kenya reported receiving weight loss advice from a health professional. Individual characteristics, such as women, living in urban areas, having more than secondary education, and being obese, were significantly associated more with the likelihood of receiving weight loss advice from a health professional. Interventions and initiatives targeted at physicians are needed to tackle the growing noncommunicable disease prevalence in Kenya.

\section{Acknowledgements}

This research did not receive funding from any source. No conflicts of interest, sources of financial support, corporate involvement, and patent holdings, exist with each of the authors. Institutional review board approval was not required nor obtained for this manuscript.

The authors would like the thank the Kenya Ministry of Health, the Kenya National Bureau of Statistics, and the World Health Organization for conducting and releasing the 2015 Kenya STEPwise Survey for Non-Communicable Diseases Risk Factor Report.

\section{Conflict of interest}

None declared.

\section{References}

1. Ng M., Fleming T., Robinson M., Thomson B., Graetz N., Margono C., ... \& Abraham JP. (2014). Global, regional, and national prevalence of overweight and obesity in children and adults during 1980-2013: a systematic analysis for the Global Burden of Disease Study
2013. The Lancet, 384(9945), 766-781. doi: 10.1016/ S0140-6736(14)60460-8

2. Abubakari AR, Lauder W, Agyemang C, Jones M, Kirk A, \& Bhopal RS. (2008). Prevalence and time trends in obesity among adult West African populations: a meta-analysis. Obesity Reviews, 9(4), 297-311. doi: 10.1111/j.1467-789X.2007.00462.x

3. Ministry of Health: Division of Non-Communicable Diseases: Kenya stepwise survey for non-communicable diseases risk factors 2015 report. (2015).

4. The World Bank. Republic of Kenya urbanization review. (2016). Washington D.C., United States: Retrieved from http://documents.worldbank.org/curated/en/639231468043512906/Kenya-urbanization-review.

5. The World Bank. GDP per capital: Kenya. (2016). Washington D.C., United States: Retrieved from https://data.worldbank.org/indicator/NY.GDP.PCAP. $\mathrm{CD}$ ? locations $=\mathrm{KE}$.

6. Demmler KM, Ecker O \& Qaim M. (2018). Supermarket shopping and nutritional outcomes: A panel data analysis for urban Kenya. World Development, 102, 292-303. doi: 10.13140/RG.2.2.28713.60009

7. Kenya National Bureau of Statistics Kenya 2014 demographic and health survey. (2014). Nairobi, Kenya. 8. Christensen DL, Eis J, Hansen AW, Larsson MW, Mwaniki DL, Kilonzo B, ... \& Friis H. (2008). Obesity and regional fat distribution in Kenyan populations: impact of ethnicity and urbanization. Annals of Human Biology, 35(2), 232-249. doi: 10.1080/03014460801949870 9. Ettarh R, Van de Vijver S, Oti S, \& Kyobutungi C. (2013). Peer Reviewed: Overweight, Obesity, and Perception of Body Image Among Slum Residents in Nairobi, Kenya, 2008-2009. Preventing Chronic Disease, 10. doi: $10.5888 / \operatorname{pcd} 10.130198$

10. Steyn NP, Nel JH, Parker WA, Ayah R., \& Mbithe D. (2011). Dietary, social, and environmental determinants of obesity in Kenyan women. Scandinavian Journal of Public Health, 39(1), 88-97. doi: 10.1177/1403494810384426 11. Banjeree ES, Herring SJ, Hurley KE, Puskarz K, Yebernetsky K, LaNoue M. (2017). Overcoming Obesity: A Mixed Methods Study of the Impact of Primary Care Physician Counseling on Low-Income African American Women Who Successfully Lost Weight. American Journal of Health Promotion, 32(12). doi: 10.1177/0890117117690853

12. Dorsey R., \& Songer T. (2011). Peer reviewed: lifestyle behaviors and physician advice for change among overweight and obese adults with prediabetes and diabetes in the United States, 2006. Preventing chronic disease, $8(6)$. 
13. Harris CL, Strayhorn G, Moore S, Goldman B, \& Martin MY. (2016). Perceived physician-informed weight status predicts accurate weight self-perception and weight self-regulation in low-income, African American Women. Journal of Health Care for the Poor and Underserved, 27(3), 1441-1463. doi: 10.1353/hpu.2016.0140 14. Jackson SE, Wardle J, Johnson F, Finer N, Beeken RJ. The impact of a health professional recommendation on weight loss attempts in overweight and obese British adults: a cross-sectional analysis. BMJ Open. 2013;3(11):e003693. doi:10.1136/bmjopen-2013-003693. doi: 10.1136/bmjopen-2013-003693

15. Lorts C \& Ohri-Vachaspati P. (2016). Peer Reviewed: Disparities in Who Receives Weight-Loss Advice From a Health Care Provider: Does Income Make a Difference?. Preventing Chronic Disease, 13. doi: 10.5888/ pcd13.160183

16. Phelan SM, MW Yeazel, WL Hellerstedt, JM Griffin, M Van Ryn (2015). Impact of weight bias and Stigma on quality of care and outcomes for patients with obesity. Obesity Reviews 16, 319-326. doi: 10.1111/obr.12266 17. Bhuiyan AR, Gustat J, Srinivasan SR et al. (2003) Differences in body shape representations among young adults from a biracial (Black-White), semirural community: the Bogalusa Heart Study. Am J Epidemiol. 158, 792-797. doi: 10.1093/aje/kwg218

18. Puoane T, Lungiswa Tsolekile, Nelia Steyn (2015). Perceptions about Body Image and Size among Black African Girls Living in Cape Town. Ethnicity and Disease, Vol. 20, pp 29-34.

19. NCD Risk Factor Collaboration. (2016). Trends in adult body-mass index in 200 countries from 1975 to 2014: a pooled analysis of 1698 population-based measurement studies with $19 \cdot 2$ million participants. The Lancet, 387(10026), 1377-1396. doi: 10.1016/S01406736(16)30054-X

20. Franz MJ, Boucher JL, Rutten-Ramos S, \& VanWormer JJ. (2015). Lifestyle weight-loss intervention outcomes in overweight and obese adults with type 2 diabetes: a systematic review and meta-analysis of randomized clinical trials. Journal of the Academy of Nutrition and Dietetics, 115(9), 1447-1463. doi: 10.1016/j. jand.2015.02.031

21. Pool AC, Kraschnewski JL, Cover LA, Lehman EB, Stuckey HL, Hwang KO, ... \& Sciamanna CN. (2014). The impact of physician weight discussion on weight loss in US adults. Obesity Research \& Clinical Practice, 8(2), e131-e139. doi: 10.1016/j.orcp.2013.03.003
22. Malan Z, Mash B, \& Everett-Murphy K. (2015). A situational analysis of training for behaviour change counselling for primary care providers, South Africa. African Journal of Primary Health Care \& Family Medicine, 7(1), 1-10. doi: 10.4102/phcfm.v7i1.731

23. Burke TF, Hines R, Ahn R, Walters M, Young, D, Anderson RE, ... \& Nelson BD. (2014). Emergency and urgent care capacity in a resource-limited setting: an assessment of health facilities in western Kenya. BMJ Open, 4(9), e006132. doi: 10.1136/bmjopen-2014-006132

24. Abarca-Gómez L, Abdeen ZA, Hamid ZA, AbuRmeileh, NM, Acosta-Cazares B, Acuin C, .. \& Agyemang C. (2017). Worldwide trends in body-mass index, underweight, overweight, and obesity from 1975 to 2016: a pooled analysis of 2416 population-based measurement studies in $128 \cdot 9$ million children, adolescents, and adults. The Lancet, 390(10113), 2627-2642. doi: 10.1016/S0140-6736(17)32129-3

25. GBD 2015 Obesity Collaborators. "Health effects of overweight and obesity in 195 countries over 25 years." New England Journal of Medicine 377.1 (2017): 1327. doi: 10.1056/NEJMoa1614362

26. Bodnar LM, Ness RB, Markovic N, Roberts JM. (2005). The risk of preeclampsia rises with increasing prepregnancy body mass index. Annals of Epidemiology, 15(7), 475-482. doi: 10.1016/j.annepidem.2004.12.008 27. Binanay CA, Akwanalo CO, Aruasa W, Barasa FA, Corey GR, Crowe S, ... \& Kibosia J. (2015). Building sustainable capacity for cardiovascular care at a public hospital in Western Kenya. Journal of the American College of Cardiology, 66(22), 2550-2560. doi: 10.1016/j. jacc.2015.09.086

28. Breitkopf CR, Egginton JS, Naessens, JM, Montori, VM, Jatoi A. (2012). Who is counseled to lose weight? Survey results and anthropometric data from 3,149 lower socioeconomic women. Journal of Community Health, 37(1), 202-207. doi: 10.1007/s10900-011-9437-8

29. Dutton GR, Herman KG, Tan F, Goble M, Dancer-Brown M, Van Vessem N, Ard JD. (2014). Patient and physician characteristics associated with the provision of weight loss counseling in primary care. Obesity Research \& Clinical Practice, 8(2), e123-e130. doi: 10.1016/j.orcp.2012.12.004

30. Stanford FC, Johnson ED, Claridy MD, Earle RL, Kaplan LM. (2015). The role of obesity training in medical school and residency on bariatric surgery knowledge in primary care physicians. International Jjournal of Family Medicine, 2015. doi: 10.1155/2015/841249 